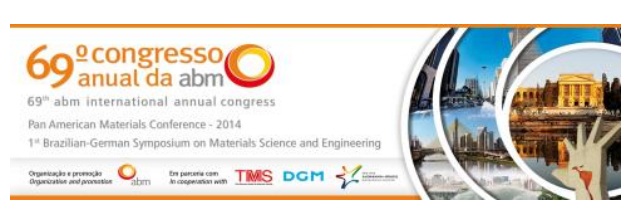

Tema: Diagramas de fases e transformações de fases

\title{
ESTUDO COMPARATIVO DO COMPORTAMENTO MECÂNICO E EVOLUÇÃO ESTRUTURAL DE CHAPAS DE AÇOS 304L SUBMETIDOS A ENSAIO CLC*
}

\author{
Isabela Santana de Oliveira ${ }^{1}$ \\ Andersan dos Santos Paula² \\ Marcelo Costa Cardoso ${ }^{3}$ \\ Luciano Moreira Pessanha ${ }^{4}$ \\ Maria Carolina dos Santos Freitas ${ }^{5}$
}

\section{Resumo}

O aço inoxidável 304L pode apresentar uma característica particular: transformações de fase induzidas por deformação, o efeito TRIP (Transformation Induced Plasticity) que possui embasamento na transformação martensítica. Neste trabalho propõe-se analisar o perfil de formação de martensita em corpos de prova submetidos a ensaio CLC (Curva Limite de Conformação), segundo o método Marciniak, nas regiões junto à trinca e distantes da mesma através de uma sonda portátil de um ferritoscópio. Utilizando técnicas de difração de Raios-X (DRX) e ensaios de dureza Vickers pode-se correlacionar a evolução microestrutural e valores de dureza nessas mesmas regiões ao grau de encruamento da austenita e a formação de martensita.

Palavras-chave: Aço inoxidável austenítico 304L; Efeito TRIP; Transformação martensítica; Ensaio CLC.

\section{COMPARATIVE STUDY OF MECHANICAL BEHAVIOR AND STRUCTURAL EVOLUTION OF 304L STEEL PLATES SUBJECT TO FLC TEST}

\section{Abstract}

The 304L stainless steel can present a particular feature: the phase transformations induced deformation, the effect TRIP (Transformation Induced Plasticity) having basis in martensitic transformation. This paper aims to analyze the profile of formation of martensite in specimens submitted for testing FLC (Forming Limit Curve), according to Marciniak method in regions close to and distant crack of the same through a handheld probe a ferritoscope. Using technique of X-ray diffraction (XRD) and Vickers hardness test was possible correlated the microstructural evolution and hardness values in those regions to the austenite hardening degree and martensite formation.

Keywords: Austenitic stainless steel 304L; Effect TRIP; Martensitic transformation, FLC Test

1 B.Sc. Engenheira, Mestranda do Programa de Pós-graduação em Engenharia Metalúrgica (PPGEM), Universidade Federal Fluminense (UFF), Volta Redonda, RJ, Brasil.

2 D.Sc., Professora do VMT e PPGEM, UFF, Volta Redonda, RJ, Brasil.

M.Sc., Doutorando do PPGEM, UFF, Volta Redonda, RJ, Brasil.

D.Sc., Professor do VEM e PPGEM, UFF, Volta Redonda, RJ, Brasil.

D.Sc, Professora do VEM, UFF, Volta Redonda, RJ, Brasil.

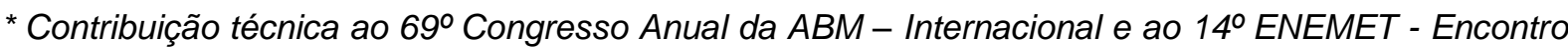
Nacional de Estudantes de Engenharia Metalúrgica, de Materiais e de Minas, 21 a 25 de julho de 2014, São Paulo, SP, Brasil. 


\section{INTRODUÇÃO}

Os aços inoxidáveis austeníticos têm como sua principal característica a retenção da austenita CFC (cúbica de face centrada) à temperatura ambiente por meio de elementos de liga como o níquel. Não possuem propriedades magnéticas e endurecem apenas por deformação a frio conferindo uma resistência mecânica maior se comparado ao mesmo procedimento aplicado em aços comuns [1]. Além disso, o aço mencionado é considerado um aço com efeito de transformação de fase induzida por plasticidade (TRIP) [2].

F.D. Fischer [2] define o efeito TRIP como um aumento significativo da plasticidade durante a mudança de fase. Ele afirma também que se o carregamento externo corresponder à tensão equivalente do material e for menor que o limite de escoamento do mesmo, a deformação plástica deve ocorrer. Em condições de trabalho a frio onde o material é plasticamente deformado gerando o efeito TRIP, a deformação homogênea pertencente à fase austenítica, que no caso dos aços inoxidáveis austeníticos, suporta essa transformação, resulta na transformação martensítica: transformação de fase no estado sólido ausente de difusão, resultante de um movimento coordenado e/ou cooperativo entre os átomos da fase matriz e que mantém uma estreita correspondência de reticulado entre a fase matriz e a fase resultante, porém, agora, com nova estrutura cristalina.

De acordo com Bresciani Filho [3] o termo conformabilidade plástica pode ser definido como a capacidade do metal, ou da liga metálica, poder ser processada por deformação plástica sem apresentar defeitos ou fratura nas peças trabalhadas. Sendo que vários fatores podem intervir na qualidade do produto final, tais como a taxa de deformação, a forma de deformação ou o tipo de tensão a que o material é submetido.

Makkouk, et al. [4], segundo a metodologia Marciniak, determinaram a curva limite de conformação para o aço inoxidável austenítico 304L na estricção e na fratura. Eles adotaram um sistema de aquisição de imagens baseado em uma marcação aleatória através de spray branco e preto. Assim, foi possível correlacionar as imagens com os intervalos de tempo relativos ao movimento de punção tendo como resultado as trajetórias de deformação para cada largura que conduziram a fratura.

O objetivo do presente estudo consistiu em avaliar o perfil de formação de martensita nas regiões junto à trinca e distantes da mesma com auxílio de uma sonda portátil de um ferritoscópio bem como as características mecânicas e microestruturais das distintas regiões analisadas quanto ao grau de encruamento da austenita e formação de martensita (CCC - cúbica de corpo Centrada), com auxílio das técnicas de difração de Raios-X (DRX) e medidas de dureza.

\section{MATERIAIS E MÉTODOS}

\subsection{Materiais}

O material objeto de estudo no presente trabalho refere-se a um aço inoxidável austenítico, classificado como 304L, o qual foi fornecido pela empresa Aperam South America. De acordo com os dados repassados pelo fornecedor, o material foi previamente laminado quente até espessura de $2,85 \mathrm{~mm}$, sendo posteriormente laminado a frio até a espessura $1,0 \mathrm{~mm}$ e largura de $500 \mathrm{~mm}$. Ao final do processamento, a chapa foi recozida a temperatura de encharque de

\footnotetext{
* Contribuição técnica ao $69^{\circ}$ Congresso Anual da ABM - Internacional e ao 14ํㅡㄹ ENEMET - Encontro Nacional de Estudantes de Engenharia Metalúrgica, de Materiais e de Minas, 21 a 25 de julho de 2014, São Paulo, SP, Brasil.
} 


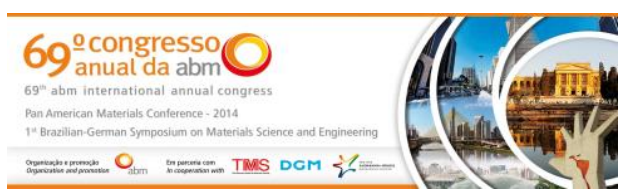

aproximadamente $1060^{\circ} \mathrm{C}$. A composição química do material é mostrada na Tabela 1.

Tabela 1. Composição Química do Aço Inoxidável Austenítico 304L em estudo

\begin{tabular}{lcccccccc}
\hline \multicolumn{1}{c}{ Elementos (\% em peso) } \\
\hline $\mathrm{C}$ & $\mathrm{Mn}$ & $\mathrm{Si}$ & $\mathrm{P}$ & $\mathrm{S}$ & $\mathrm{Cr}$ & $\mathrm{Ni}$ & $\mathrm{Mo}$ & $\mathrm{Al}$ \\
\hline 0,018 & 1,269 & 0,479 & 0,030 & 0,002 & 18,364 & 8,022 & 0,026 & 0,003 \\
\hline $\mathrm{Cu}$ & $\mathrm{Co}$ & $\mathrm{V}$ & $\mathrm{Nb}$ & $\mathrm{Pb}$ & $\mathrm{B}$ & $\mathrm{Ti}$ & $\mathrm{Sn}$ & $\mathrm{W}$ \\
\hline 0,042 & 0,102 & 0,042 & 0,007 & 0,001 & 0,006 & 0,002 & 0,004 & 0,015 \\
\hline Fonte: Aperam South America
\end{tabular}

Conforme os resultados de ensaios mecânicos realizados nos laboratórios do fornecedor, o material apresenta dureza de 81,9 HRB, limite de escoamento (LE) de $316 \mathrm{MPa}$ (a 0,2\% de deformação), limite de resistência a tração (LR) de $671 \mathrm{MPa}$ e alongamento total $(A L)$ de $55 \%$. Valores estes dentro da faixa de especificação do material: (i) LE entre 240 e $370 \mathrm{MPa}$, (ii) LR entre 580 a $750 \mathrm{MPa}$, e (iii) AL entre 50 a $67 \%$.

\subsection{Métodos}

As amostras extraídas da chapa aço inoxidável 304L foram submetidas a ensaios de CLC realizados no Centro de Tecnologia da empresa USIMINAS por meio de uma máquina de ensaios de embutimento Erichsen modelo 242, equipada com o sistema de aquisição e correlação de imagens digitais ViaLUX, e o software Autogrid para depuração das deformações nos corpos de prova. Foram assim testados corpos de prova (CP) com larguras iguais a 20, 40, 60, 80, 100, 120, 130, 140, 180 e 220 todos com comprimento de $220 \mathrm{~mm}$ segundo a direção perpendicular ao sentido de laminação da chapa, conforme a Tabela 2.

Tabela 2. Medidas dos corpos de prova e das máscaras utilizados nos ensaios de CLC segundo a metodologia de Marciniak

\begin{tabular}{|c|c|c|c|}
\hline \multicolumn{2}{|c|}{ Corpo de Prova } & \multicolumn{2}{|c|}{ Máscara } \\
\hline Nomenclatura & Medida (mm) & Cortado ao Meio & $\begin{array}{l}\text { Diâmetro do furo } \\
\text { central (mm) }\end{array}$ \\
\hline 020 & $20 \times 220$ & \multirow{4}{*}{ Sim } & \multirow{4}{*}{ Sem furo } \\
\hline 040 & $40 \times 220$ & & \\
\hline 060 & $60 \times 220$ & & \\
\hline 080 & $80 \times 220$ & & \\
\hline 100 & $100 \times 220$ & \multirow{7}{*}{ Não } & \multirow{4}{*}{44} \\
\hline 120 & $120 \times 220$ & & \\
\hline 130 & $130 \times 220$ & & \\
\hline 140 & $140 \times 220$ & & \\
\hline 150 & $150 \times 220$ & & 36 \\
\hline 180 & $180 \times 220$ & & 34 \\
\hline 220 & $180 \times 220$ & & 32 \\
\hline
\end{tabular}

Fonte: Dissertação de Mestrado de M.C. Cardoso, UFF/PPGEM, 2012 [5].

De acordo com a metodologia Marciniak, foi necessária a confecção de máscaras que devem ser posicionadas entre o punção e corpo de prova de modo a garantir que a fratura ocorra na zona central. Estas máscaras foram usinadas com as mesmas dimensões dos corpos de prova e com o aço inoxidável 304L avaliado neste trabalho. Máscaras bipartidas obtidas por corte em guilhotina foram empregadas para os corpos de prova com larguras de 20, 40, 60 e $80 \mathrm{~mm}$.

\footnotetext{
* Contribuição técnica ao 69ำ Congresso Anual da ABM - Internacional e ao 14ํㅡㄹ ENEMET - Encontro Nacional de Estudantes de Engenharia Metalúrgica, de Materiais e de Minas, 21 a 25 de julho de 2014, São Paulo, SP, Brasil.
} 


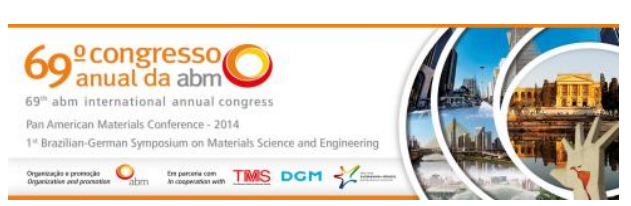

Máscaras com furo central usinado com diâmetro igual a $44 \mathrm{~mm}$ foram confeccionadas para os corpos de prova com larguras de 100, 120, 130 e $140 \mathrm{~mm}$. Outras três máscaras também foram confeccionadas com furo central igual a 36, 34 e $32 \mathrm{~mm}$ de diâmetro a fim de serem usadas no ensaio CLC dos corpos de prova de larguras 150, 180 e $220 \mathrm{~mm}$, respectivamente. As dimensões e os desenhos dos corpos de prova utilizados estão apresentados na Tabela 2 e nas Figuras 1 e 2.
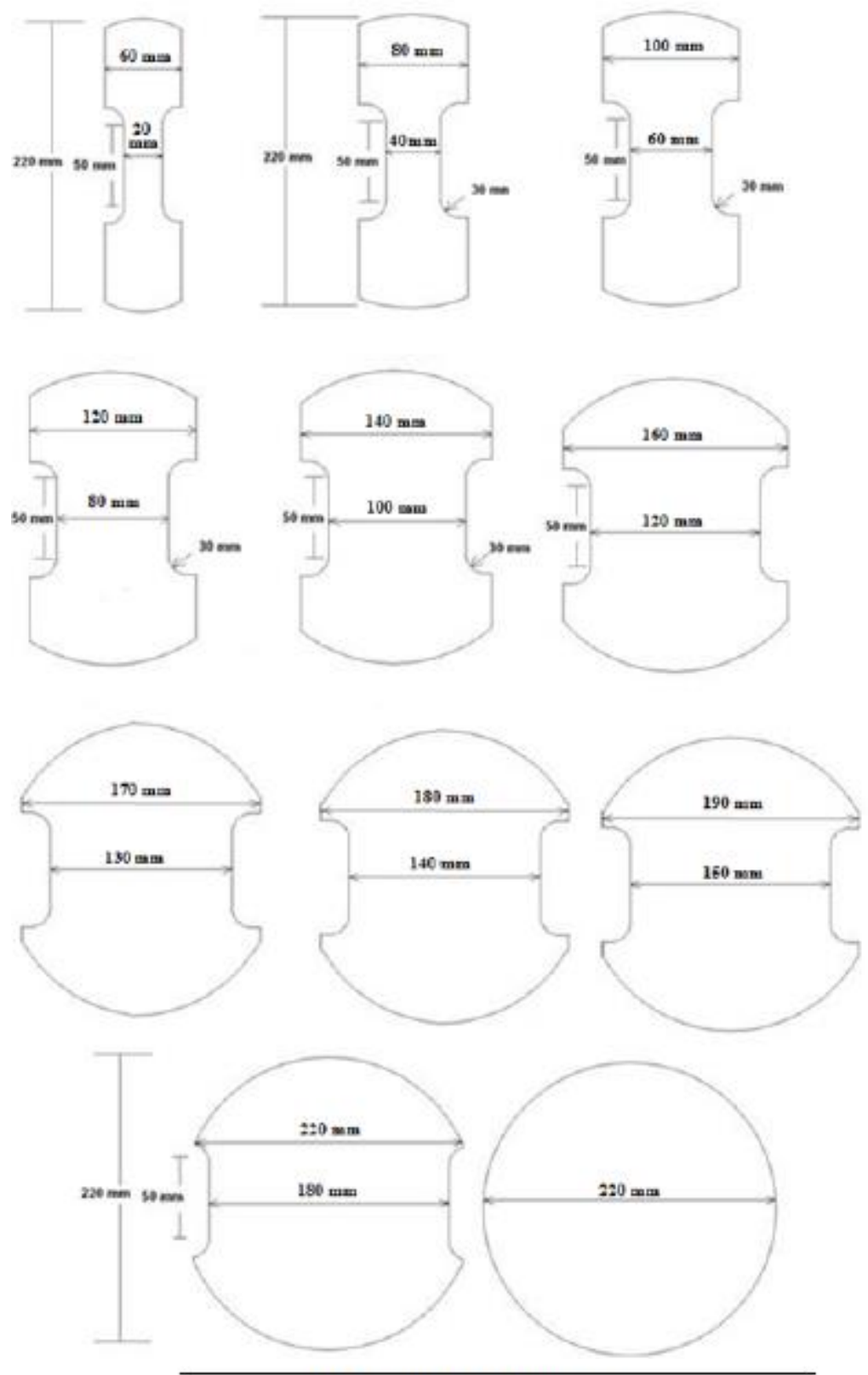

Direção de laminação

Figura 1. Corpos de prova dos ensaios de CLC segundo a metodologia de Marciniak [6].

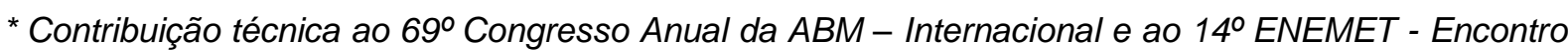
Nacional de Estudantes de Engenharia Metalúrgica, de Materiais e de Minas, 21 a 25 de julho de 2014, São Paulo, SP, Brasil. 


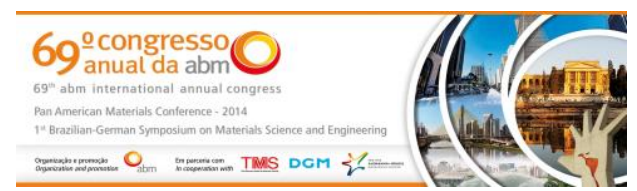

Concluídas as medidas com o ferritoscópio, os corpos de prova do ensaio CLC foram seccionados (com auxílio de corte por eletroerosão) para extração de amostras em regiões selecionadas em relação a linha central (com largura de 2 nós a direita e a esquerda da linha central, e comprimento de 5 nós da linha da fratura) e as linhas laterais (com largura de 2 nós a direita e a esquerda das linhas laterais "B" e " $C$ ", e comprimento de 5 nós da linha da fratura) de modo a poder-se analisar as fases presentes (austenita e martensita) nas amostras do aço em estudo com o auxílio da técnica de difração de raios-x. As mesmas foram comparadas com o material na condição como recebida. $O$ difratômetro que foi utilizado é o modelo XRD-6000-SHIMADZU, a radiação incidente do tipo Co Ka $(\lambda=1,78897 \AA$ ) com 30 $\mathrm{kV}$ de tensão e $30 \mathrm{~mA}$ de corrente, na geometria Bragg-Brentano. A variação das intensidades dos picos foram medidas com base no acoplamento $\theta / 2 \theta$, variando $2 \theta$ de $40^{\circ}$ a $110^{\circ}$ com passo de $0,02^{\circ}$ num modo de varredura contínuo. Com base na literatura [26] as fases associadas aos planos foram identificadas como:

- Austenita (CFC - $\gamma$ - A): (111), (200) e (220);

- Martensita (CCC - $\alpha^{\prime}-$ M): (110), (200) e (211).

E, por fim, as duas amostras para medidas de dureza, uma de cada lado das amostras extraídas para análise de DRX, foram seccionadas com auxílio do corte por eletroerosão (com largura de 2 nós, e comprimento de 5 nós da linha da fratura) de modo a ser embutidas a frio, a fim de evitar alguma alteração microestrutural e mecânica por meio um ciclo de aquecimento elevado, com o auxílio de uma resina e de um catalisador da marca Arotec com temperatura de cura próxima a $80^{\circ} \mathrm{C}$, e tempo de cura em torno de 12 horas. Posteriormente as amostras passaram por um lixamento com lixas de carbeto de silício nas seguintes granulometrias: 320, 400, 500, 800, 1000 e 1200 mesh, sob refrigeração com água; e por um polimento em pano de feltro, inicialmente com pasta de diamante de 6,3 e $1 \mu \mathrm{m}$, com uso de lubrificante polimento de ferrosos com diamante (marca Arotec), e por um polimento final com solução aquosa de alumina (20:1 em volume) de 0,05 $\mu \mathrm{m}$ com uso de água destilada com lubrificante. Esta preparação metalográfica foi realizada para se obter as medidas de dureza ao longo da espessura.

Os ensaios de dureza Vickers (HV) foram realizados utilizando um microdurômetro da marca Shimadzu, modelo HMV-2T (instalado no laboratório de Metalografia da EEIMVR/UFF), com penetrador de diamante de forma piramidal com base quadrada da marca, com um ângulo de $136^{\circ}$ entre as fases opostas da pirâmide. A carga utilizada foi de $100 \mathrm{~g}$ com tempo de manutenção a carga máxima de 20 segundos. Foram realizadas medições em cada amostra em pontos da sua espessura com perfil similar ao que será adotado para as medidas com o ferristoscópio. De maneira a não se obter valores associados com linha de segregação central do material não foram realizadas medidas no centro da espessura das amostras. As medidas foram feitas ao longo da direção DL a $1 / 4$ da espessura (frente - corpo de prova extraída entre as linhas "B" e "D" da Figura 3 ) e a $3 / 4$ (verso - corpo de prova extraída entre as linhas "C" e "D" da Figura 3) de modo a se averiguar a evolução da propriedade mecânica dureza associada às faces interna e externa dos corpos de CLC.

\section{RESULTADOS E DISCUSSÃO}

A Figura 4 mostra a curva CLC na estricção e na fratura oriunda das amostras de diferentes larguras para o aço inoxidável austenítico 304L. Nota-se um domínio de

\footnotetext{
* Contribuição técnica ao $69^{\circ}$ Congresso Anual da ABM - Internacional e ao 14ํㅡㄹ ENEMET - Encontro Nacional de Estudantes de Engenharia Metalúrgica, de Materiais e de Minas, 21 a 25 de julho de 2014, São Paulo, SP, Brasil.
} 


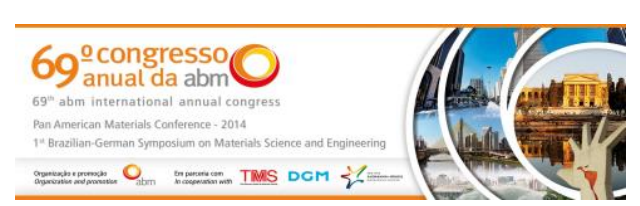

deformação biaxial, com o corpo de prova de diâmetro de 220, uma queda da maior deformação principal na superfície igualmente observados nas literaturas [4,7].

Pelo gráfico apresentado na Figura 4 é possível inferir que à medida que a largura do corpo de prova aumenta, existe uma tendência do estado de deformação caminhar em direção a um estado de deformação plana.

O ensaio CLC comprovou que o corpo de prova 040 e o 100 foi o que mais se aproximou de uma trajetória de deformação correspondente à tração uniaxial onde $\varepsilon_{1}=-2 \varepsilon_{2}$. Já o 020, 060, 080,120, 140 e 150 estão em uma zona de transição entre as trajetórias de deformação de tração uniaxial e deformação plana. $\mathrm{E}$, os corpos de prova 180 e 220 foram os que mais se aproximaram de um estiramento no qual $\varepsilon_{1}=$ $\varepsilon_{2}$. A figura 4 resume a disposição das deformações oriundas do ensaio além da curva CLC resultante do mesmo.

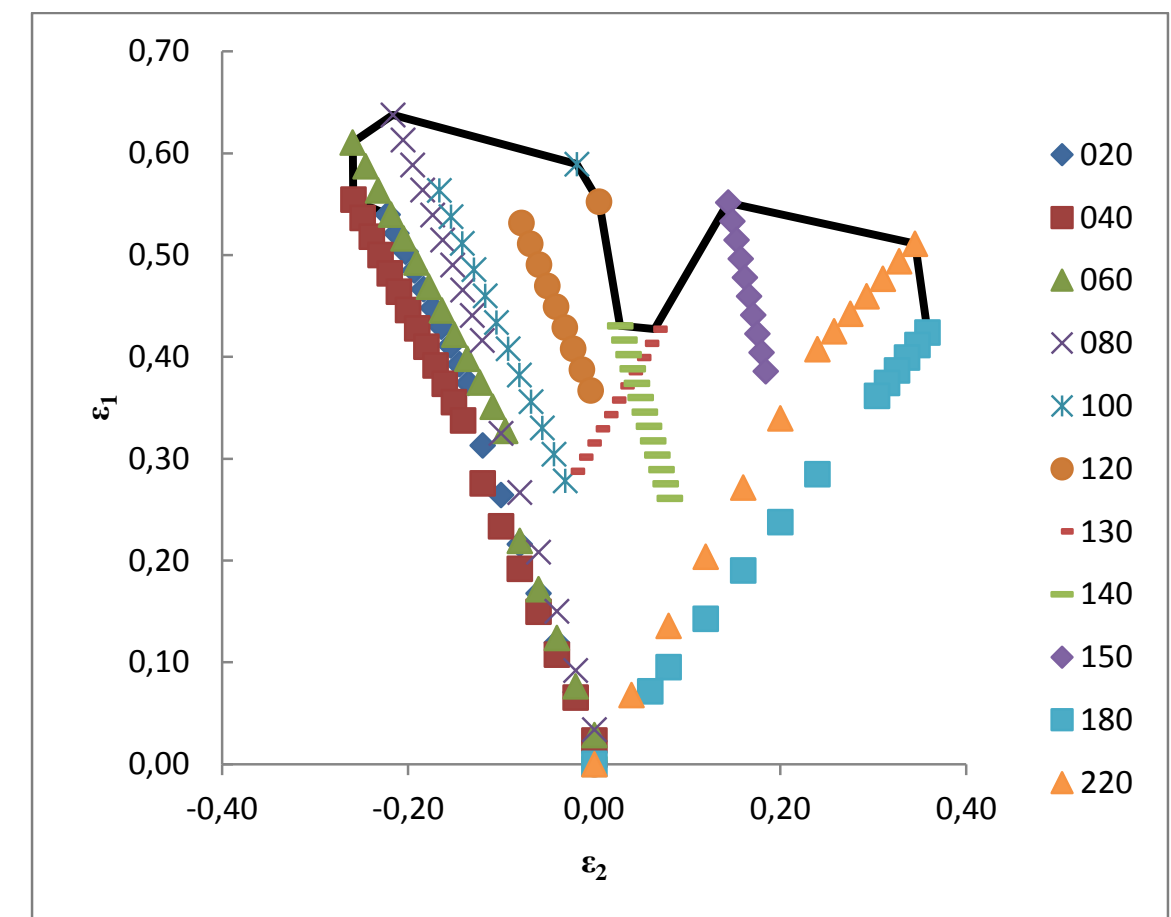

Figura 4. CLC na estriç̧ão e fratura obtida para o aço inox austenítico 304L.

Os percentuais medidos com a sonda do ferritoscópio na linha central se mostraram mais estáveis na superfície vinculada ao verso dos corpos de prova, em detrimento da intensidade que se apresentou maior na superfície vinculada à frente dos mesmos. À medida que a largura dos corpos prova aumentava o percentual de martensita se tornava mais intenso e mais instável evidenciando uma formação heterogênea desta fase conforme os dados apresentados na Figura 5.

Tendo em vista que o perfil de martensita medido com a sonda portátil do Ferristoscópio foi similar, fazendo-se a relação entre a largura e o percentual de martensita, para as linhas laterais "B" e "D" apresentadas na Figura 3, escolheu-se apresentar neste trabalho os resultados referentes a linha traçada na lateral dos corpos de prova vinculada a linha "B". Porém, quando se trata de intensidade, as medições feitas na linha lateral dos corpos de prova se mostraram ligeiramente maiores no verso se comparadas com as feitas no verso da linha central, conforme Figura 6. Este resultado se deve à posição da linha lateral estar mais próxima do contorno da área útil do corpo de prova marcado na Figura 3, isto significa que a

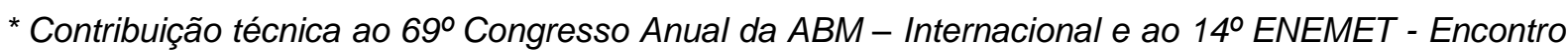
Nacional de Estudantes de Engenharia Metalúrgica, de Materiais e de Minas, 21 a 25 de julho de 2014, São Paulo, SP, Brasil.
} 
região sofre a influência das deformações impostas pelo contorno do punção durante o ensaio CLC.

Os corpos de prova 020, 040 e 060 apresentaram uma queda considerável no percentual de martensita tanto na frente quanto no verso em todas as linhas analisadas, enquanto que o corpo de prova 220 obteve os maiores percentuais frente, verso, linha central e lateral. De um modo geral, o verso dos corpos de prova, independente da linha mensurada, mostrou uma quantidade menor de martensita gerada se comparado à frente dos mesmos.

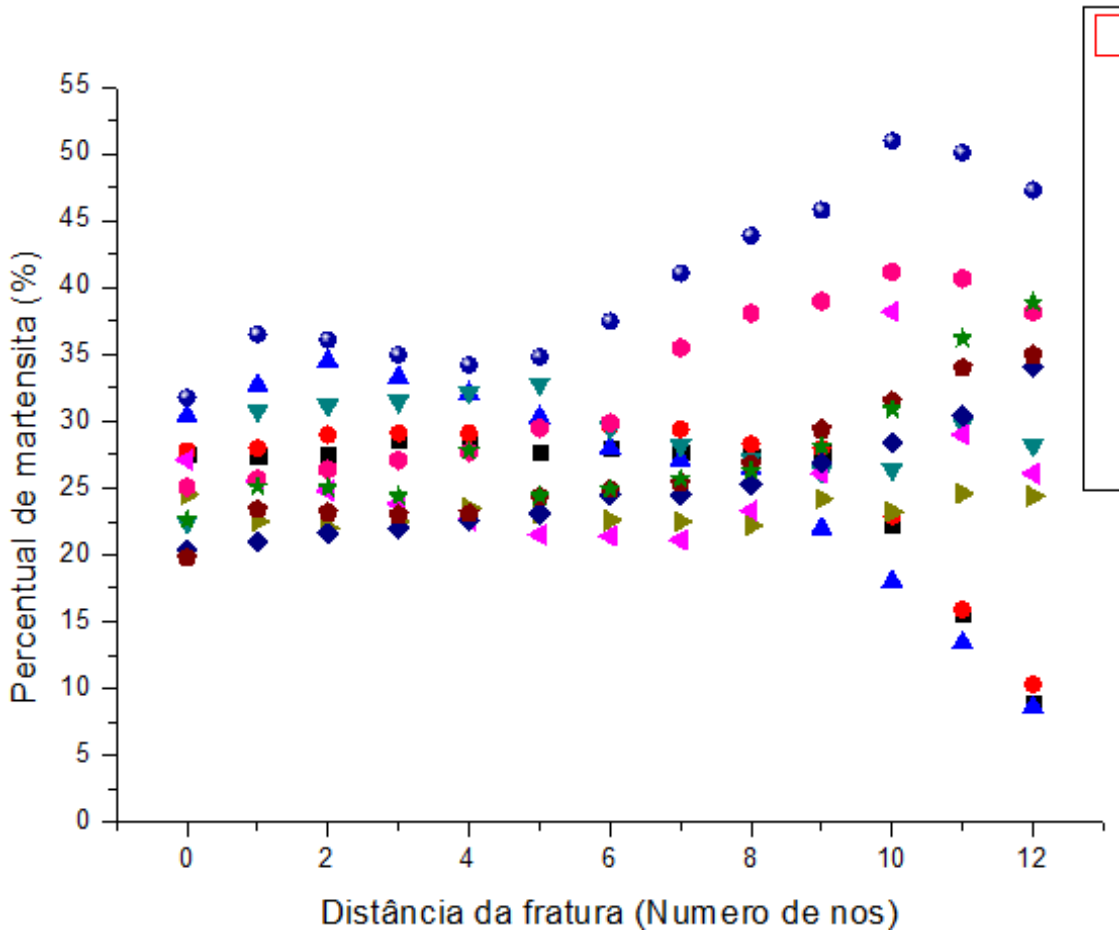

(a)

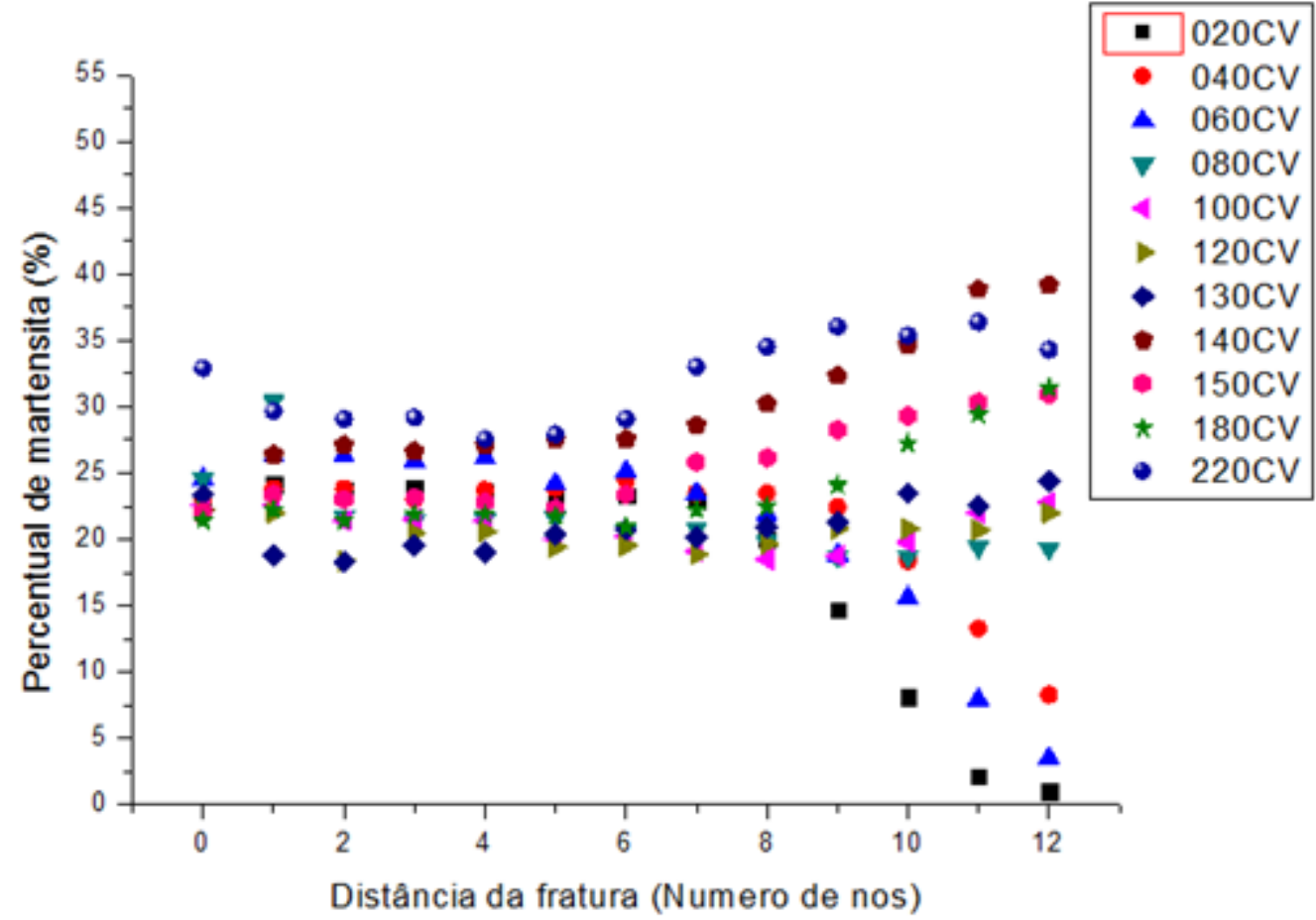

(b)

Figura 5. Percentual de martensita ao longo da linha central traçada nos corpos de prova, frente (CF) e verso (CV) associados à linha "C" da Figura 3.

* Contribuição técnica ao 69ํㅡㄹ Congresso Anual da ABM - Internacional e ao 14ํㅡㄹ ENEMET - Encontro Nacional de Estudantes de Engenharia Metalúrgica, de Materiais e de Minas, 21 a 25 de julho de 2014, São Paulo, SP, Brasil. 

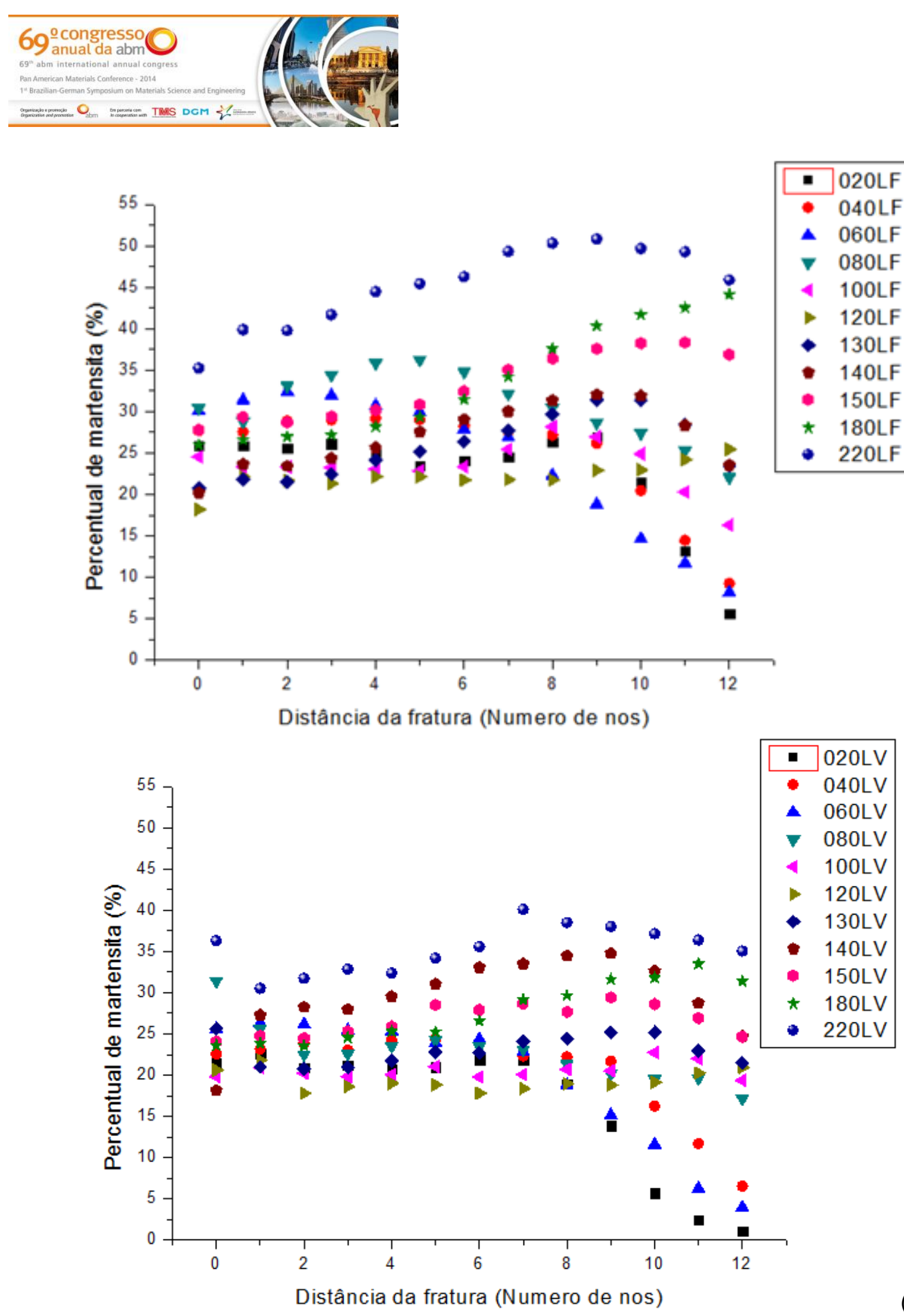

(a)

(b)

Figura 6. Percentual de martensita ao longo da linha lateral traçada nos corpos de prova, frente (LF) e verso (LV) associados à linha "B" da Figura 3.

Com base nos corpos de provas para análise de DRX extraídas ao redor da linha central e linhas laterais (linhas "C" e "B", respectivamente, apresentada na Figura 3), as análises realizadas através da técnica de difração de raios-x confirmaram o consumo de austenita em todos os corpos de prova acarretando o surgimento de novos picos de martensita, $M(200)$ e $M(211)$, que se tornaram cada vez intensos à medida que a largura dos corpos de prova CLC aumentava. A Figura 7 apresenta os espectros de DRX revelando os picos presentes para as fases austenita e martensita nas superfícies associadas à frente e ao verso da linha central de cada corpo de prova.

* Contribuição técnica ao 69 Congresso Anual da ABM - Internacional e ao 14ํㅡㄹ ENEMET - Encontro Nacional de Estudantes de Engenharia Metalúrgica, de Materiais e de Minas, 21 a 25 de julho de 2014, São Paulo, SP, Brasil. 


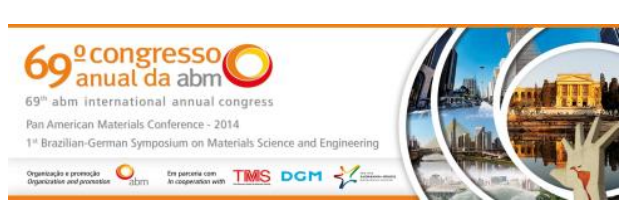

as larguras de corpos de prova superiores $100 \mathrm{~mm}$, inclusive, as quais transitam da tração pura para o deformação plana até se aproximar do estado de expansão biaxial (Figura 4), onde as orientações da martensita de maiores intensidades são atribuídas a (200) e (211) em detrimento da orientação (111), conforme Figura 7. Com base numa análise mais detalhada, foi observado também que a posição dos picos se deslocou para a direita em relação aos existentes na amostra como recebida. Para os picos formados devido ao ensaio CLC, $M(200)$ e $M(211)$, a posição foi a mesma tanto para o centro analisando frente e verso em cada corpo de prova como mostra a Figura 7. A partir desses resultados foi possível inferir que houve um encruamento devido a dois fatores: o deslocamento do pico de austenita $A(111)$ e o aumento da largura à meia altura do pico de martensita $M(200)$ segundo o aumento da largura dos corpos de prova.

A fim de manter a lógica dos resultados já apresentados, as medições de dureza Vickers também foram realizadas tendo como referência a distância da fratura, em duas posições específicas da espessura: a $1 / 4$ da espessura, ou seja, representando a dureza próxima à superfície frente, e a outra a 3/4 da espessura representando à superfície verso. A Figura 8 mostra a evolução do perfil da dureza próxima à superfície denominada de frente e a outra denominada de verso de algumas das amostras, selecionadas com base nos aspectos distintos verificados na análise de DRX. Nota-se que a dureza próxima à superfície frente apresenta valores superiores que aquela próxima à superfície verso, independente da largura do corpo de prova, - que está de acordo com os valores superiores de percentual de martensita medidos com ferritoscópio (Figura 6). Os valores obtidos indicam que trajetórias de estiramento tendem a produzir um maior grau de endurecimento as trajetórias de deformação plana e tração uniaxial, conforme o perfil da configuração da curva CLC (Figura 8 comparada a Figura 4), as quais revelaram nas análises de DRX (Figura 7) maiores evidências de encruamento da austenita e conjunto a formação da segunda fase martensita. Comportamento que possivelmente acarreta uma maior contribuição ao endurecimento devido ao encruamento do que devido à fração de martensita formada.

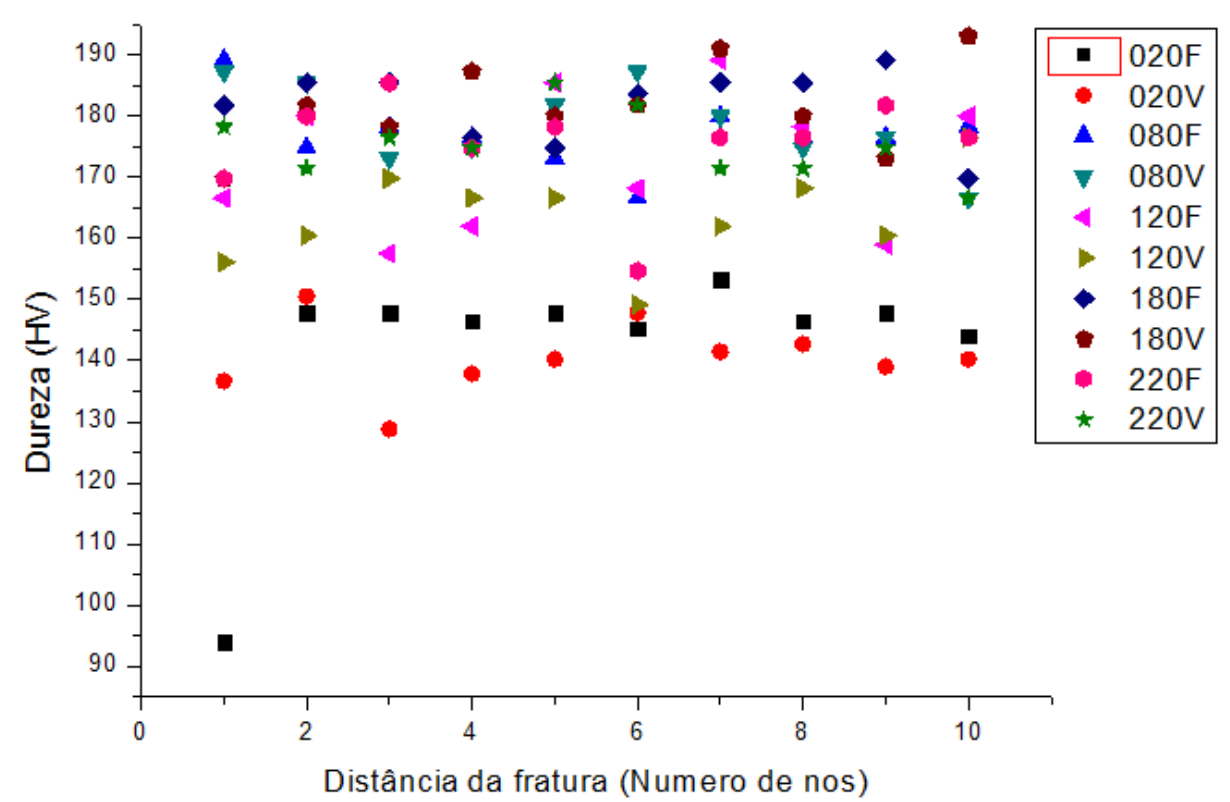

Figura 8. Medidas de dureza para uma seleção de amostras comparando as superfícies externa (Frente) e interna (Verso) associado às medidas do perfil a $1 / 4$ e $3 / 4$ da espessura, respectivamente, a partir da fratura.

\footnotetext{
* Contribuição técnica ao $69^{\circ}$ Congresso Anual da ABM - Internacional e ao 14ํㅡㄹ ENEMET - Encontro Nacional de Estudantes de Engenharia Metalúrgica, de Materiais e de Minas, 21 a 25 de julho de 2014, São Paulo, SP, Brasil.
} 


\section{CONCLUSÃO}

Baseado em todos os ensaios realizados junto aos seus respectivos resultados conclui-se que:

- Os percentuais de martensita foram mais heterogêneos na superfície denominada de frente dos corpos de prova, se comparados com a superfície denominada de verso destes. Acredita-se que o fenômeno ocorreu devido ao contato direto com a máscara utilizada no ensaio, embora esta minimize o atrito. Porém estes resultados são mais evidentes nos resultados respectivas a análise de ferristocopia do que na simples análise do perfil dos espectros de DRX;

- A largura dos corpos de prova também se mostrou como um fator de influência na formação de martensita e no encruamento da austenita. $O$ aumento da largura do corpo se mostrou favorável à formação de martensita, com exceção das regiões de larguras intermediárias próximas a condição do estado plano de deformação e de expansão biaxial. Ou seja, a transição do estado de deformação embutimento profundo, passando pela tração uniaxial e posterior distanciamento do estado plano de deformação em direção ao estado de expansão biaxial, são condições favoráveis a indução de martensita, enquanto as demais ao encruamento da austenita.

\section{Agradecimentos}

Os autores agradecem ao CNPq, PQ2, Capes e Faperj pelo suporte financeiro; a Aperam South America pelo material fornecido.

\section{REFERÊNCIAS}

1 Carbó HM. Aços Inoxidáveis: aplicações e especificações. ArcelorMittal InoxBrasil. 2008 [acesso em 20 out. 2012] Disponível em: ftp://ftp.demec.ufpr.br/disciplinas/EngMec_NOTURO/TM343/artigo_acoinox_aplicacao_ especificacao.pdf.

2 Fischer FD, Reisner G, Werner E, Tanaka K; Cailletaud G; Antretter T. A New View on Transformation Induced Plasticity (TRIP). International Journal of Plasticity, 2000; 16:723-748.

3 Bresciani Filho E, Zavaglia CAC, Button ST, Gomes E, Nery FAC. Conformação Plástica dos Metais. 4⿳亠丷a edição. Editora da UNICAMP; 1991.

4 Makkouk BR, Serri N, Bolle J, Martiny B, Teaca M, Ferron MG. Experimental and theoretical analysis of the limits to ductility of type 304 stainless steel sheet. European Journal of Mechanics - A/Solids, 2008; 27:181-194.

5 Cardoso MC. Avaliação do Comportamento Plástico de uma Chapa de Aço Inoxidável Austenítico 304L por meio de Ensaios de Tração Uniaxial e Curva Limite de Conformação [Mestrado]. UFF; 2012.

6 Cardoso MC, Moreira LP, Freitas MCS, Paula AS. Avaliação da Curva Limite de Conformação de um Aço Inoxidável Austenítico. $7^{\circ}$ Congresso Brasileiro de Engenharia de Fabricação. 2013.

7 Hecker SS, Stout MG, Staudhammer KP, Smith JL. Effects of strain state and strain rate on deformation-induced transformation in 304 stainless steel.Part I. Magnetic measurements and mechanical behavior. Metall, 1982; 13:619-626.

\footnotetext{
* Contribuição técnica ao $69^{\circ}$ Congresso Anual da ABM - Internacional e ao 14ํㅡㄹ ENEMET - Encontro Nacional de Estudantes de Engenharia Metalúrgica, de Materiais e de Minas, 21 a 25 de julho de 2014, São Paulo, SP, Brasil.
} 